\title{
Physical Environment of a Coffee Shop Analysis of Future Customers Expectation Views
}

\author{
Siti Aisyah Muhammad, Sung Pil Lee
}

\begin{abstract}
Customer satisfaction is very important in business world to gain loyalty and revisited customers. This paper aims to study the customer perceived experience as the first time visitor to a coffee shop related to their expectation and satisfaction in two coffee shops in namely in Seomyeon, Busan, South Korea. The methodology apply interviews, surveys and analysis using Semantic Differences and AMOS 22. The findings shows that the customers usually have been introduced about the coffee shop through social media network influenced by the reviews and viral comment. The first time customers also were not coffee lovers but the physical environment explorers or the social media influencers. The components of the physical enviornment consist of the facility aesthetic, lighting, ambience, layout, service product and social factors. The taste of the food and beverages was not the main priority for the customers to decide about revisiting the coffee shop. Customers also willing to recommend to others if they were satisfied with the services provided. The results also examined that cultural context influenced the preferences in selecting and revisiting the coffee shops.
\end{abstract}

Keywords: coffee shop; interior; physical environment; design; customer

\section{INTRODUCTION}

The world of service market is very much relying on the environmental psychology Environmental psychologists suggest that the feelings or the emotions of the people determine what they do and how they do it (Donovan \& Rossiter, 1982; Mehrabian \& Russel, 1974). Perception, in addition, is the instant response to the immediate environment, whereas cognition refers to the process of semantic and verbal classification of perception (Bro, 2000). Impression and customer's behavioral intention that are related with the customer's satisfaction whereby physical environment and cognitive emotion do take the decision upon their retention and revisiting the place (Han et al., 2009; Hyun et al., 2011; Ha \& Jang, 2013). Coffee shop nowadays not only a food and beverages business but also provide service to customers such as meeting area, wifi and event hall. A study argued that the physical environment has relationship with the customers' preferences upon selecting the coffee shops (Muhammad \& Lee, 2016).

Revised Manuscript Received on July 22, 2019.

Siti Aisyah Muhammad, Faculty of Architecture and Ekistics Universiti Malaysia Kelantan, 16300 Bachok, Kelantan, Malaysia School of Design, DongSeo University

Sung Pil Lee, School of Design, DongSeo University, 47 Jurye-ro, Jurye 2(i)-dong, Sasang-gu, Busan, South Korea

\section{PHYSICAL ENVIRONMENT}

Findings have shown that innovation takes place in five distinct design areas, which, directly or indirectly influence the customer experience, namely the physical environment, the service employees, the service delivery process, fellow customers and back office support (Voss \& Zomerdijk, 2007). The physical environment is what will be emphasized in this research. Landscape architects, architects, interior designers, retailers, and environmental psychologists have acknowledged the influence of physical environments on behavior (Donovan \& Rossiter, 1982; Turley \& Milliman, 2000). It has been argued that human behavior is strongly associated with the physical environment (Mehrabian \& Russel, 1974; Russel \& Pratt, 1980). An environmental psychologists like Mehrabian and Russel's (1974) came out with a theory that individuals generally react to the environment in two opposite ways: approach and avoidance. As said, convincing physical surroundings stimulate emotional/physical responses as well as cognitive responses such as customer beliefs/perceptions (Bitner, 1992; Golledge, 1987). Moreover, Rapoport (1982) agreed that in a cognitive viewpoint, the physical environment is described as a form of nonverbal communication, which is also called object language. As summarized from Mehrabian and Russell (1974), the physical environment is considered a key variable influencing customer perceptions and behavior and has been studied from the perspective of environmental psychology. It also agreed that physical environment's role in retail atmospherics (Kotler, 1973; Turley and Milliman, 2000) and also 'servicescapes' (Bitner, 1992).'Servicescape' carried a meaning as "the man-made, physical surroundings as opposed to the natural or social environment" (Bitner, 1992, p. 58). Wakefield and Blodgett studied the effects of layout accessibility, facility aesthetics, electronic equipment, seating comfort, and cleanliness on the servicescape and it found that physical environment significantly affected customer satisfaction (1999). In fact, Mattila and Wirtz indicated that the top three reasons for customers to patronize their target restaurants in the casual dining sector were food quality, service, and atmosphere (2001). 


\section{Physical environment of a coffee shop Analysis of Future Customers Expectation views}

Furthermore, in the context of retailing, atmospherics was a sentient design of physical environment that created the impact in consumers prone to purchase probability (1973). Kotler (1973) suggested four environmental dimensions: visual, aural, olfactory, and tactile. Then, Berman and Evans (1995) drawn-out atmospheric stimuli or elements in four categories: the exterior of the store, the general interior, the layout and design variables, and the point- of-purchase and decoration variables.

Earlier, Hall (1966) described three types of environmental cues: fixed feature elements (such as walls and floors), semi-fixed feature elements (such as furniture type and arrangement, window displays) and non- fixed feature elements (such as ambiance and people in the environment). Followed by Baker (1986) provided a taxonomy of environment cues consisted of design factors, social factors, and ambient factors. Later, the field of environmental psychology and service innovation researchers have suggested the extended essential factors of the physical environment, such as décor and artifacts, spatial layout, and ambient conditions that are particularly pertinent to the service industry (e.g., Nguyen \& Leblanc, 2002; Raajpoot, 2002; Wakefield \& Blodgett, 1999).

\section{THEORETICAL FRAMEWORK}

Satisfied customers produce positive perception and prone to loyalty. Perceived value is posited as a factor of customer satisfaction. Perceived value can be improved by either adding benefits to the service or by reducing the outlays associated with the purchase and use of the service (Lovelock, 2001). Perceived service quality represents the discrepancy between customers' expectations and their perceptions of the service performance (Lewis and Booms 1983; Grönroos 1984; Parasuraman et al. 1988). Referring to Tam (2010), the definitions of perceived value generally involve a trade-off between what customers receive and what they give up to acquire the service (Zeithaml 1988; Monroe 1991). Issanchou stated that consumer' expectation and perceptions, however are depended on both intrinsic and extrinsic cues (1996). Intrinsic cues include inherent sensory qualities such as the taste, appearance and scent while extrinsic cues are external elements that influence the customers for instance the price, brand and also personal and situational variables. Cardello (1996) added that these intrinsic and extrinsic cues must be investigated in order to understand the consumers' food preferences. Findings from Park (2004), there are two factors of consumer values in eating-out in Korea namely utilitarian value and hedonic value. Utilitarian value customer has described as a practical, task-related and rational behavior customer by Batra and Ahtola (1991) while the hedonic value was a personal and resulted from spontaneous, fun and playfulness than task completion (Holbrook and Hirschman, 1982). Thus, Park (2004) simplified as, "the utilitarian value of eating-out is defined as a value related to functional and economical aspects of eating-out while the hedonic value represents consumer fun, entertainment, absorbing, and novelty" (p. 89, 2004). Voss and Zomerdijk have proposed experiential innovation journey for a service process (2007). 'Servicescape' is an important element of customer psychology (e.g. emotion, satisfaction) and behavior (e.g. patronage, positive word of mouth) when service is consumed (Wakefield \& Blodgett, 1994). Lin (2004) has appeared with a model of the relationship between cognitive and emotion towards servicescape, categorized into macro-perspective and micro-perspective antecedents. A microperspective includes antecedents that affect perception at the personal level whilst macroperspective consists of antecedents that outside of individual control. All antecedents in micro and macro perspectives could be considered as intervening variables of customer's cognitive process and emotional response in servicescape (Fig. 1).

\section{METHODOLOGY}

This study has selected two location for the case study in a city in Busan, South Korea. A comparative analysis about the customers preferences in selecting the coffee shop and intention of revisiting. A pre-test survey has been done with 20 samples in order to decide the most visited and want to be visited coffee shop according to the expectation of the taste and the physical environment of the coffee shops in both locations. In Busan, the two coffee shops were selected with the same criteria, which was local Korean franchise coffee shop and were located within 100m bounds (Fig. 2). Based on the result, two different styles of coffee shops were selected namely OK Dabang and KAVAN Espresso. Semantic Differential Method (SDM) consists semantic attributes of the product to analyze and carried out where the sample must assess the product according to their favorable. The attributes were gained from pretest was used KJ method (Muhammad and Lee, 2016). The proposed hypothesis by Ryu (2012) about the attributes of physical environment was adapted in this study consisted of facility aesthetic, lighting, ambience, layout, service product and social factors. Then 100 participants were asked to fill up the questionnaires without visiting the places (male: 49, female: 51) where 61\% were the Design Students and 39\% were from the others category (4\%: unemployed; $9 \%$ : arts or entertainment field; $16 \%$ education field; $4 \%$ financial field; $3 \%$ public servant; $2 \%$ health care field; $1 \%$ real estate field). A video and a photographic image of $\mathrm{OK}$ Dabang and KAVAN Espresso were shown at the beginning of the answering session. 


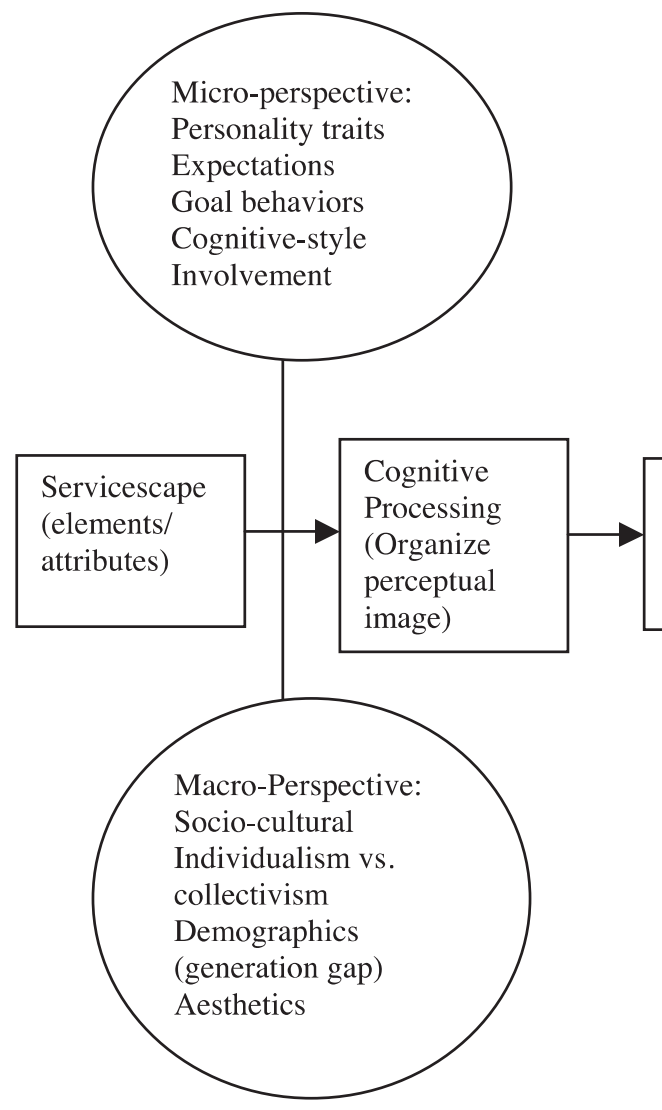

Fig. 1: Customer evaluation process of a 'servicescape'

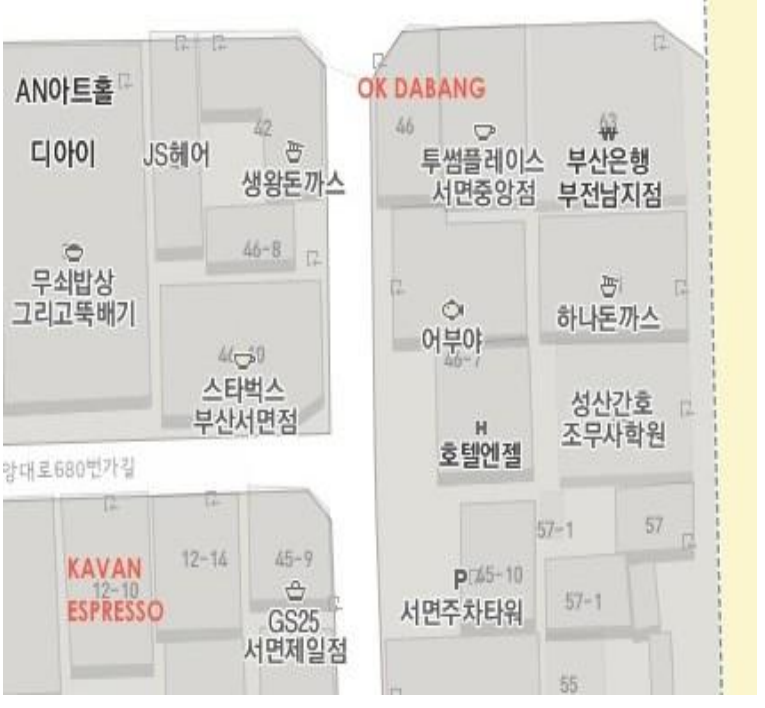

Fig. 2: Location of OK Dabang and KAVAN Espresso

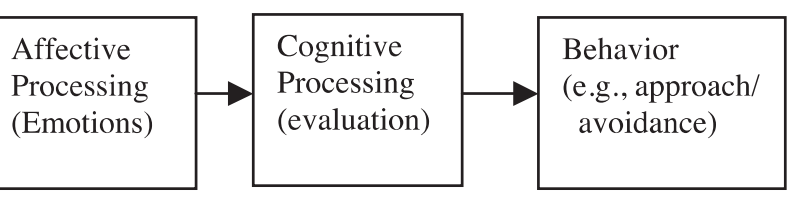

\section{FINDINGS AND ANALYSIS}

Historically, the coffee shop in South Korea begins with dabang after the Japanese colonization (1910-1945) with a very different westernized style and only the royal and the high positions people could afford it. Later in the 1970s, the concept of dabang that involve the DJ playing recorded music upon the request of the customers. Then, the competition among the dabangs in 1980 have created many styles and ideas of its atmosphere and started to be called as a café. In the 1990s, the people thought that the consumption had a style too. Thus, they preferred the cafés with neater interior designs and emphasize professionalism in the coffee choice.

Then, there was a huge shift in the Korean café culture's history in 1999 when Starbucks, the first foreign franchise coffee shop in Korea, was established in Sinchon, Seoul. Starbucks introduced Korea to a new café culture, such as take-out and self-service system without a good-looking waitress and the customer staying at a café alone while reading a book or doing homework. Since then, more foreign franchise coffee shops entered the market with a greater variety of coffee and atmospheres, and more local franchise cafés and small private-owned cafés appeared with their unique features (Jang, 2012). The impression is usually affected by the senses, reviews, social media, and personal experiences that had become a part of the marketing concept. OK Dabang has started its business in the year 2005 and currently has 7 franchises until the year 2014. It continues the tradition of the dabang atmosphere where the DJ and music request are provided. OK Dabang in Seomyeon, Busan has been opened in the year 2011 at the corner of a two-storey building. Located at the same junction with OK Dabang, KAVAN Espresso has been opened since the year 2012 that has brought a different atmosphere than OK Dabang. KAVAN Espresso follows the contemporary industrial design interior with modern gallery look. Fig. 3 (a)(b) shows the entrances of OK Dabang and KAVAN Espresso. 


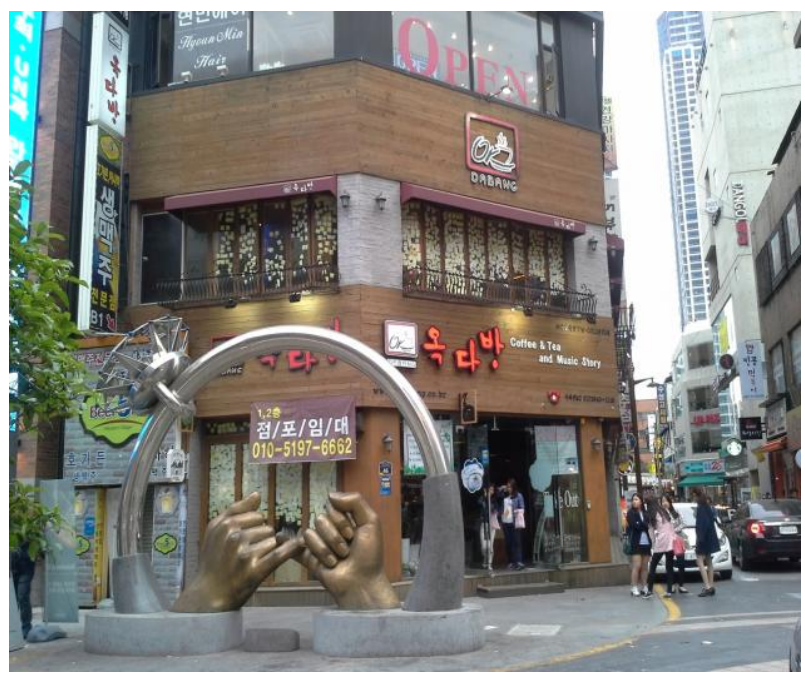

Fig. 3 (a): OK Dabang

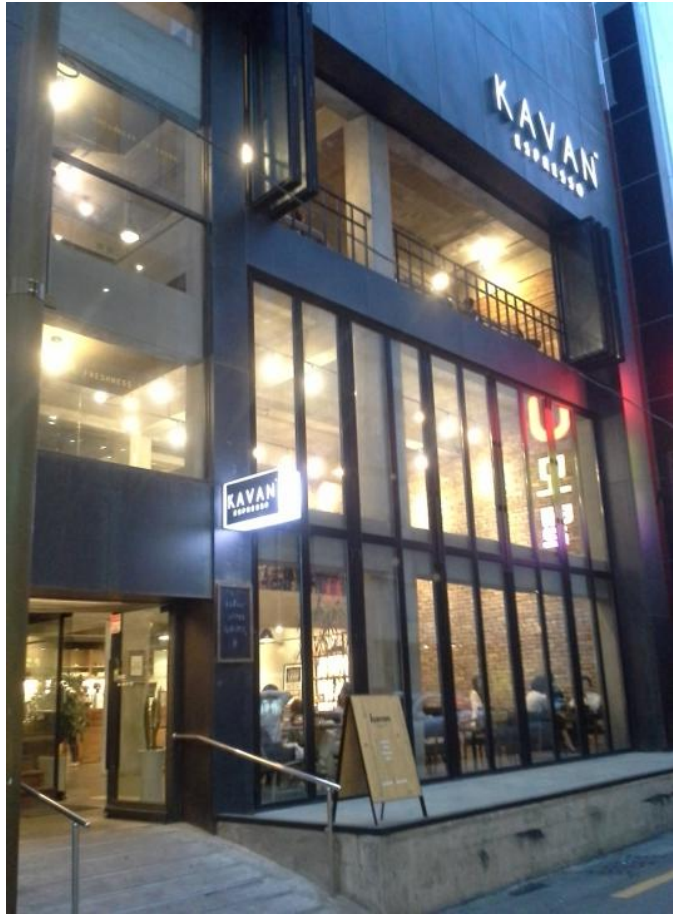

Fig. 3 (b): KAVAN Espresso

The attributes were gained from pretest used KJ method resulted 101 keywords (Fig. 4) where A represents kAVAN Espresso and B represented OK Dabang. The keywords were clustered according to the proposed attributes of physical environment by previous researcher (Ryu,2012).

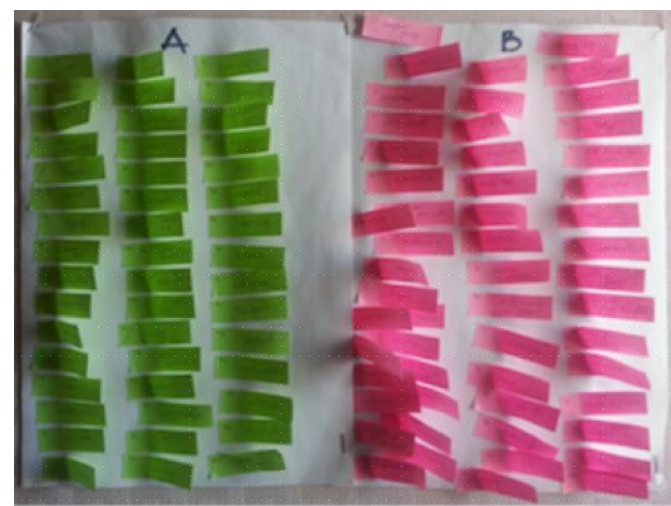

Fig. 4: 101 keywors from KJ Method
TABLE 2: The photographic images of OK Dabang

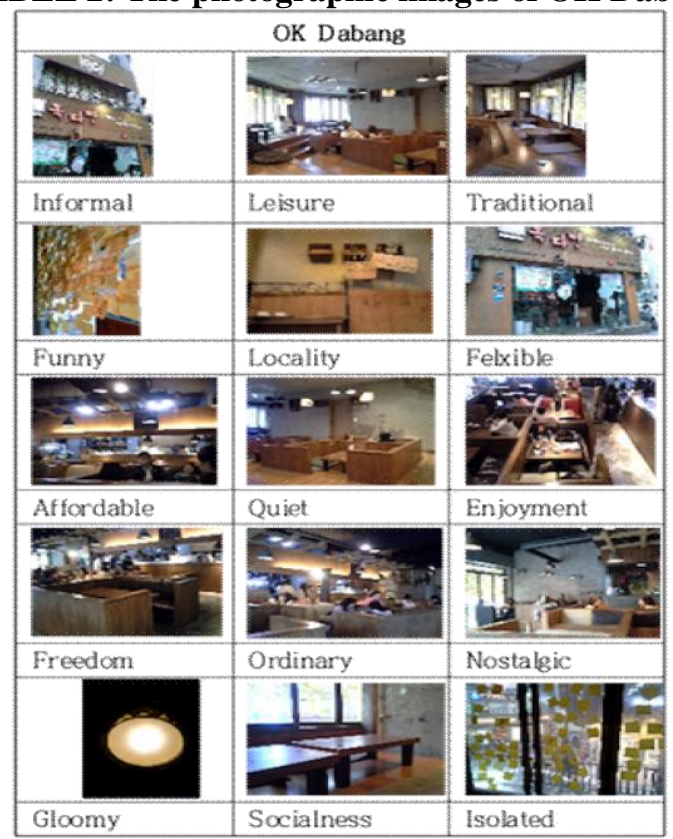

TABLE 3: The photographic images of KAVAN

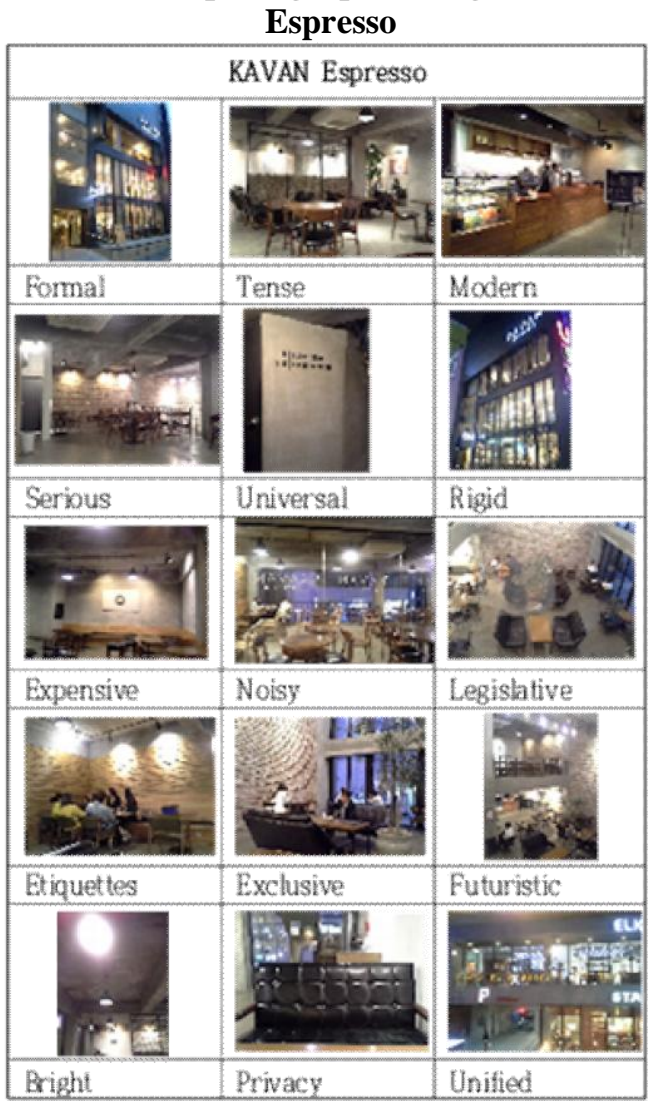

The example of the physical environment of both coffee shops as presented to the participants as shown in Fig. 5 and Fig. 6.

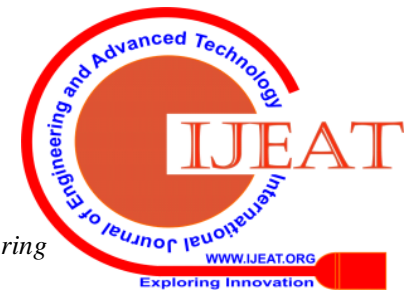




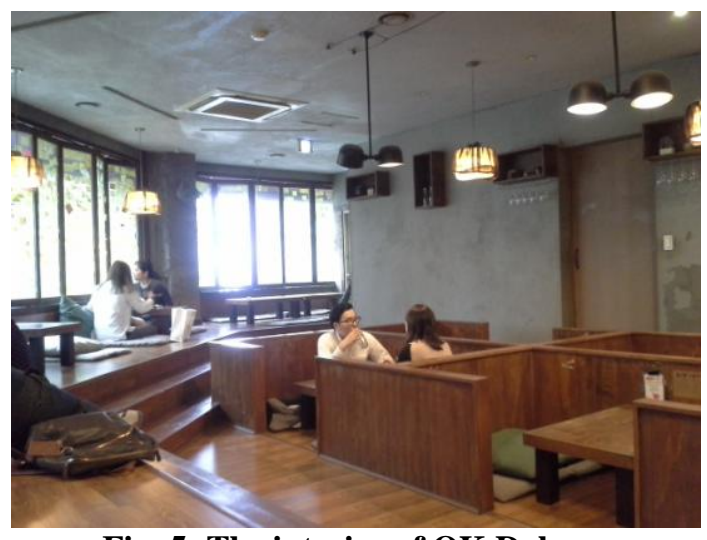

Fig. 5: The interior of OK Dabang

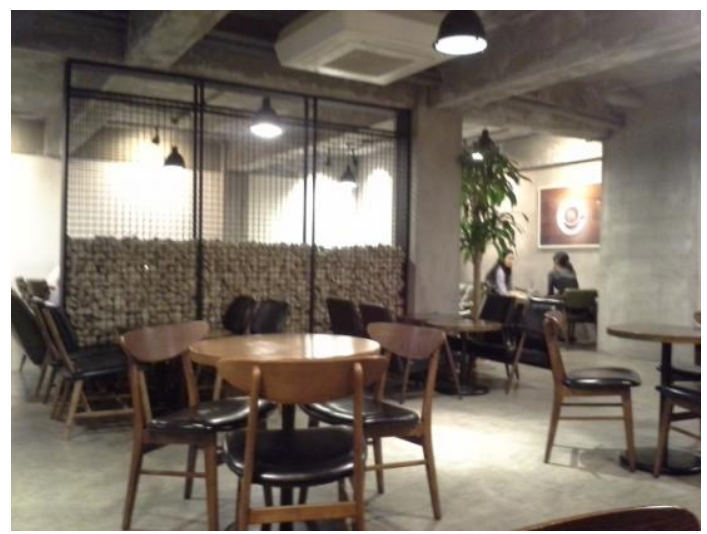

Fig. 6: The interior of KAVAN Espresso

The attributes were defined by pairs of antonymous adjectives, which lie at either end of a qualitative scale. Derived from the adjectives given by the samples, 15 pair's adjectives were clustered according to the similar and highest repetition of meanings in Table 1 . It was proven that the proposed classification by Ryu (2012) has represented the expectation and the impression of the future customers by viewing the physical environment of the specific coffee shops. The results of 5-bipolar (Fig. 7 and Fig. 8) show that significant comparative impression between both coffee shops.

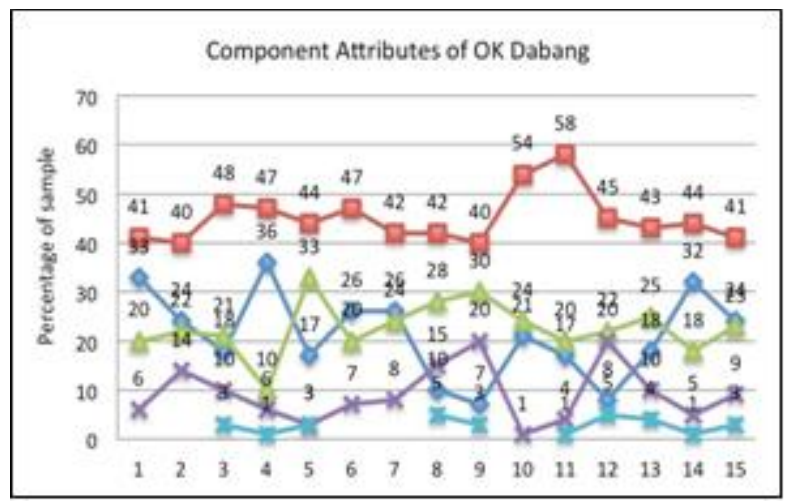

Fig.7: Scattered chart for OK Dabang

TABLE 1: The 5-bipolar scale of pairwise matrix for both coffee shops

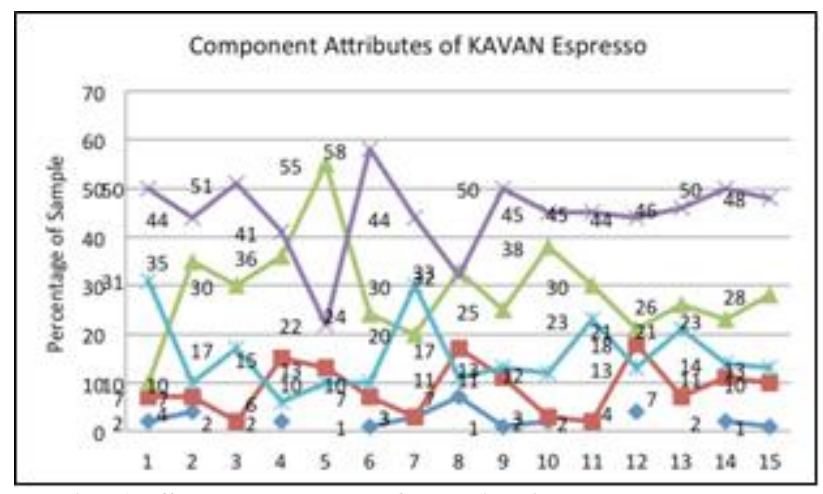

Fig. 8: Scattered chart for KAVAN Espresso

These future customers also stated their opinion about the coffee shop as below:

"I am prefer OK Dabang because it looks more relaxful and seems people do not care my attire"

"I think that KAVAN Espresso looks more exclusive and not suitable for group of students"

"The design of KAVAN Espresso more sophisticated and I prefer to go there"

"If I want to convince my client, I would invite him to meet at KAVAN Espresso"

"OK Dabang more welcoming and looks fun, people can write something and paste at the wall is so interesting"

The paticipants expectation and impression about both coffee shops are summarized as below:

1. The participants have selected the environment that most suitable with their emotions and behaviors (Bitner, 1992; Golledge, 1987).

2. The participants will observe the layout and the interior of the coffee shop before make a dicision to stay (Kotler,1973; Matilda and Witz, 2001).

3. The participants stated that the exclusivity is expected representing a good service of the coffee shop (Bitner, 1992; Lin, 2004)

\section{CONCLUSION}

The culture of the Korean who socializes while eating or drinking may result from a good quality of coffee provided by the coffee shops, thus the taste is not the main attention to select their most preferred coffee shop. Besides, as stated by Jang (2012), the limited space also resulting Korean to select the coffee shop as a gathering and meeting place than their house. Coffee shop in Korea has many functions rather than only a drinking place. It does attach with their psychology as well. The results show significant preference upon both of the coffee shops. Participants' preferred OK Dabang as enjoyment and leisure place while KAVAN Espresso as the legit and serious place. Therefore, it is agreed by Kotler, that the atmosphere has an emotional effect to the buyers that could enhance his purchase probability, as it is describable in sensory terms. 


\section{Physical environment of a coffee shop Analysis of Future Customers Expectation views}

\section{BIBLIOGRAPHY}

[1] Aisyah Muhammad, \& Sungpil Lee (2015), Factors of Customer's Preference of Visiting the Coffee Shop in South Korea, International Journal of Sciences: Basic and Applied Research (IJSBAR) Volume 24, No 7, pp 252-265

[2] Bergenwall, M. (1998). An Overview of Emotion Theory: Incorporating The Concept Of Emotion Into Service Quality Research, Meddelanden Working Papers, No. 367. Helsinki: Swedish School of Economics and Business Administration.

[3] Donovan, R.J., \& Rossiter, J.R. (1982). Store Atmosphere: An Environmental Psychology Approach,Journal of Retailing 58, 34-57.

[4] Gemser G., \& Leenders M. (2001). How integrating industrial design in the product development process impacts on company performance. The Journal of Product Innovation Management 18, 28-38.

[5] Hsiao, S.W. (1994a). Fuzzy Set Theory Applied To Car Style Design. International Journal of Vehicle Design, 15, 255-278.

[6] Hsiao, S.W. (1994b). Fuzzy Set Theory on Car-Color Design. Color Research and Application 19 (3), 202-213.

[7] Hsiao, S.W. (1994c). A Systematic Method for Color Planning In Product Design. Color Research and Application 20 (3), 191-205.

[8] Hsu, S.H., Chuang, M.C., \& Chang, C.C. (2000). A Semantic Differential Study Of Designers' And Users' Product Form Perception. International Journal of Industrial Ergonomics 25, 375391.

[9] Jang. J. H. (2012). Korean Café Culture: What Korean Cafés Mean to Koreans. Retrieved from 79-400: Global Studies Advanced Seminar. $\quad$ Retrieved from http://www.cmu.edu/dietrich/modlang/docs/polyglot/F2012/jangE.pd $\underline{\mathrm{f}}$

[10] Kim. W. G. \& Moon. Y. J. (2009). Customers' Cognitive, Emotional, and Actionable Response To The Servicescape: A Test Of The Moderating Effect Of The Restaurant Type. International Journal Of Hospitality Management, 28 (1),144-156.

[11] Ko Yu-Yuan, Lin Po-Hsien, \& Lin Rungtai. (2009). Study of Service Innovation Design in Cultural and Creative Industry, Journal of Internationalization, Design and Global Development, 5623, 376385 .

[12] K.. Ryu and S. Jang, "The Effect Of Environmental Perceptions On Behavioral Intentions Through Emotions: The Case Of Upscale Restaurants", Journal of Hospitality \& Tourism Research, 31, 56-72, 2007.

[13] M. J. Bitner, B. H. Booms and M. S. Tetreault, "The Service Encounter: Diagnosing Favorable and Unfavorable Incidents", Journal of Marketing, 54, 71-84, 1990.

[14] M. K. Brady and J. J. Cronin, "Some New Thoughts On Conceptualizing Perceived Service Quality: A Hierarchical Approach", Journal of Marketing, 65(3), 34-49, 2001.

[15] M. K. Hui, L. Dube and J. Chebat, "The Impact of Music on Consumer's Reaction to Waiting for Services", Journal of Retailing, 73, 87-104, 1997.

[16] M. Pullman and M.A. Gross, "Ability Of Experience Design Elements To Elicit Emotions And Loyalty Behaviors", Decision Sciences 35 (3), 551-578, 2004.

[17] M.J. Bitner, "Servicescape: The Impact Of Physical Surroundings On Customers and Employees", Journal of Marketing, 56, 2, 1992

[18] Ministry of Knowledge Economy, Korea's Food Industry \& The National Food Cluster, Invest Korea 2013.

[19] N. Cross, "Engineering Design Methods: Strategies for Product Design", 2nd Edition, Wiley, Chichester, 1994.

[20] N. Raajpoot, "TANGSERV: A Multiple Item Scale For Measuring Tangible Quality In Foodservice Industry", Journal of Foodservice Business Research, 5, 109-127, 2002.

[21] P. D. Hertog and R. Bilderbeek, Conceptualising Service Innovation and Service Innovation Patterns, Research Programme Strategic Information Provision on Innovation and Services (SIID) for the Ministry of Economic Affairs, Directorate for General Technology Policy, 1999.

[22] P. Kotler, "Atmospherics a s a Marketing Tool", Journal of Retailing, 49:48-64, 1973.

[23] W. Irving, 2012, Environmental Psychology: Building with Feeling by Nalina Mose, aia.org. in :Global Studies Advanced Seminar inhttp://www.aia.org/practicing/AIAB096792. (retrieved on Aug 20,2014) 